\title{
Aritmética e interdisciplinaridade: ecos da história da educação matemática
}

\section{Arithmetic and interdisciplinarity: echoes of the history of mathematical education}

\author{
Wagner Rodrigues Valente*
}

\begin{abstract}
RESUMO
O objetivo deste texto é analisar artigos do periódico Revista Educação, da década de 1930, relativos às propostas de ensino globalizante e centros de interesse de Ovide Decroly. A análise tem em vista as ponderações que professores-autores dos artigos expressam sobre 0 ensino de aritmética por meio da proposta pedagógica decroliana. Conclui-se que os artigos mostram reticências sobre a modernização pedagógica, considerando o ensino globalizante e centros de interesse, relativamente ao ensino de aritmética. As ressalvas mencionadas a essa modernização podem ser interpretadas como permanências, até a atualidade, de elementos da cultura escolar do ensino de matemática: o respeito ao programa de ensino, em termos de um conjunto de conteúdos a serem ministrados, independentemente da proposta pedagógica em voga; e a concepção de aprendizagem da matemática como sinônimo de resolução de muitos exercícios sobre um dado tema a ser estudado. Tratam-se de ecos da história da educação matemática ouvidos e pronunciados por professores da atualidade.
\end{abstract}

Palavras-chave: Ensino globalizante. Centros de interesse. Decroly. Aritmética.

* Universidade Federal de São Paulo. Guarulhos, São Paulo, Brasil. E-mail: ghemat.contato@ gmail.com. http://orcid.org/0000-0002-2477-6677. 


\begin{abstract}
The purpose of this paper is to analyze articles of the Revista Educação periodical during the decade of 1930 in relation to proposals of the teaching globalization and centers of interest of Ovide Decroly. The analysis takes into account the considerations of the authors of the articles on the teaching of arithmetic through the pedagogical approach of Decroly. It is concluded that the articles show reluctance in the pedagogical modernization, considering the teaching globalization and the centers of interest, regarding the teaching of arithmetic. The doubts mentioned to this modernization can be interpreted, until nowadays, as elements of the school culture of mathematics teaching: respect to the teaching program, in terms of a set of contents to be taught, independently of the pedagogical proposal in vogue; and the conception of learning mathematics as synonymous of solving many exercises on a particular theme to be studied. These are echoes of the history of mathematical education present in the speeches of current teachers.
\end{abstract}

Keywords: Globalization teaching. Centers of interest. Decroly. Arithmetic.

\title{
Considerações iniciais
}

O Movimento da Escola Nova, como mostram os historiadores da educação, reúne várias tendências pedagógicas. Elas, por vezes, têm como referência autores, personagens que, por meio de suas experiências e suas obras, criam verdadeiras escolas pedagógicas, no âmbito desse movimento. Esse é o caso de Ovide Decroly (1871-1932), assim como o de outros médicos que se tornaram educadores, com destaque também para Maria Montessori (1870-1952).

As propostas de Decroly têm repercussão internacional e chegam ao Brasil. Fernandes (2019) tem dedicado seus estudos às apropriações das propostas decrolianas para os ensinos de matemática nos primeiros anos escolares. Também é temática de pesquisa o ensino de matemática na pedagogia montessoriana, que vem sendo realizada por Rezende (2019). Tratam-se de trabalhos que pretendem trazer à luz o modo como a matemática para o ensino e para a formação de professores é reelaborada nas diferentes propostas pedagógicas que emergem das 
variadas tendências escolanovistas, em especial, aquelas vindas de Decroly e Montessori. Tais estudos inscrevem-se no âmbito de projeto maior de pesquisa que intenta investigar as transformações nos saberes profissionais do professor que ensina matemática no longo período de cem anos: 1890-1990, reunindo vasta gama de estudos.

Nas distantes décadas iniciais do século XX, em meio à efervescência mundial do movimento escolanovista, não é anacrônico considerar que os anseios por um ensino globalizante constituem referências históricas para a atualidade das propostas ditas interdisciplinares. Ensino globalizante e centros de interesse para ensinar aritmética no curso primário?

Este texto atém-se a uma análise pontual da recepção do ensino globalizante e centros de interesse. Estuda as reações de professores paulistas, autoridades do ensino, por meio da Revista Educação, aos processos consagrados pela pedagogia de Decroly. $\mathrm{O}$ tema a ser tratado tem em conta as dúvidas dos professores relativamente a essa pedagogia para o ensino de aritmética nos primeiros anos escolares. Ensino globalizante e centros de interesse para ensinar aritmética no curso primário?

Considera-se importante a análise dessas reações, pois elas permitem avaliar o alcance das propostas de Decroly em termos de seu impacto na cultura escolar no âmbito das diferentes matérias de ensino, em específico, da matemática (aritmética). Além disso, fazem-nos ouvir, em certa medida, os ecos da história da educação matemática presentes nas propostas atuais com motivação interdisciplinar.

\section{Sobre ensino globalizante e centros de interesse}

Ovide Decroly é personagem que se inscreve no contexto da Bélgica do início do século XX, que vive momento de profundas mudanças sociais resultantes da revolução industrial, em meio aos debates da escolarização obrigatória, ocorridos na Europa no início desse séculoAlguns anos depois, cria uma escola para crianças ditas "normais", o Ermitage, em atividade até os dias atuais, médico, psicólogo, professor universitário, pedagogo, educador e pai de família, erige-se como personalidade reconhecida de seu tempo, ocupando variados postos e funções em seu país.

A produção de Decroly tem início em 1894 com estudos concernentes exclusivamente às questões médicas. Porém, já em 1901, seus escritos vão evidenciar um novo olhar sobre as crianças consideradas "anormais". Nesse ano, Decroly funda, em Bruxelas, uma primeira escola para crianças deficientes. Alguns anos 
depois, cria uma escola para crianças ditas "normais", o Ermitage, em atividade até os dias atuais.

O lema da escola "para a vida, pela vida" é indicativo da filosofia de base dos estudos de Decroly. A partir dessa perspectiva, instala-se a ideia do global e das necessidades e interesses da criança.

Um texto importante relativamente ao ensino globalizante e centros de interesse é o de Ovide Decroly, publicado em 1929, intitulado "A função de globalização e o ensino". O texto é uma síntese de inúmeros artigos e textos escritos pelo autor desde 1906 (WAGNON, 2009).

Para o melhor entendimento das propostas de Decroly, é preciso considerar que o autor parte do princípio de que todo indivíduo entra em contato com o mundo e se desenvolve a partir de uma percepção de conjunto. O ponto de partida para o conhecimento é, então, o conjunto, o global. Desse modo, o autor considera que a globalização é um elemento e um modo de reação psíquica de todo indivíduo em seu processo de conhecimento (WAGNON, 2009).

Considerando esse caráter basilar da globalização no processo de aprendizagem, a originalidade do pensamento de Decroly expressa-se por meio dos centros de interesse. São eles pontos estruturantes da sua pedagogia. Cada indivíduo conhece o mundo a partir do sentido global, de uma forma globalizante, e os centros de interesse representam modos a partir dos quais o processo global se realiza. Para o autor, quatro são os centros de interesse: alimentar-se, lutar contra as intempéries, defender-se, agir e trabalhar. Esses pontos-chave, modos de o indivíduo se portar em sociedade, permitem a Decroly realizar a articulação entre as necessidades individuais e sociais. Assim, cada ser, e sua vida em sociedade, tem necessidades voltadas a esses quatro centros de interesse.

Dada a importância atribuída por Decroly aos centros de interesse, sua pedagogia se estrutura considerando o desafio de mobilizá-los no processo de aprendizagem. E esse processo busca não tratar os conhecimentos a serem adquiridos como disciplinas fechadas em si mesmas. $\mathrm{O}$ aluno, por meio dos centros de interesse, é levado a realizar atividades que têm em conta três etapas: observar, associar e experimentar.

Todos esses elementos estruturantes da pedagogia de Decroly nos fazem perguntar sobre os ensinos de matemática. Como a matemática está presente nas propostas decrolianas que ganham expressão no Brasil? Tal questão motiva o desenvolvimento, como se disse anteriormente, de estudos em curso. Até o presente, a revisão bibliográfica em diferentes bases de dados não revelou a existência de estudos sistematizados sobre a matemática na pedagogia decroliana ${ }^{1}$.

$1 \mathrm{O}$ catálogo de teses e dissertações da Capes, por exemplo, é revelador da ausência de estudos sobre a matemática na pedagogia de Decroly. 
Por agora, este texto atenta para a recepção da proposta de Decroly, tendo em vista o ensino de matemática. A análise considera as reações de professores preocupados com o ensino de matemática, em particular, com a aritmética dos primeiros anos escolares. Ensino globalizante e centros de interesse para ensinar aritmética no curso primário?

\section{Revistas pedagógicas e o debate para orientar professores no ensi- no de aritmética}

Ao que tudo indica, especialmente nas décadas de 1930 e 1940, há repercussão das propostas de Decroly no Brasil. E elas são registradas pelas revistas pedagógicas. Fazer uso desse tipo de documentação - revistas e impressos pedagógicos - para elucidar processos e dinâmicas escolares é algo que já de algum tempo faz parte das pesquisas relativas à história da educação. No dizer de Denice Catani, tais documentos são analisados sob a perspectiva de "evidenciar os modos pelos quais se dá a ler aos professores o que se consideram os conhecimentos pedagógicos essenciais às boas práticas" (CATANI, 1996, p. 127). Também poderíamos ajuntar a essa ponderação, sobre as revistas pedagógicas e o conteúdo que elas veiculam, que tais impressos buscam sistematizar saberes profissionais da docência, aqueles "essenciais às boas práticas".

Em especial, os números publicados pela Revista Educação constituem manancial importante com documentos que permitem analisar a recepção das propostas de ensino globalizante, em especial, aquelas de Ovide Decroly. O periódico, organizado pela Diretoria Geral do Ensino e, posteriormente, pela Secretaria de Educação do Estado de São Paulo, circula entre 1927 e 1961 (CATANI, 1996, p. 125).

No dizer de Carvalho e Cordeiro (2002, p. 22):

A iniciativa de editar uma revista, em São Paulo, a partir de 1927, insere-se num amplo conjunto de estratégias desenvolvidas nesse período no campo educacional brasileiro e paulista, como forma de constituir um veículo de divulgação das posições pedagógicas assumidas pelo grupo responsável pela sua publicação, de aquisição de prestígio por parte de seus redatores e de formação de uma opinião favorável à adoção das medidas reformistas entre o professorado e a própria opinião publica. A revista Educação cumpriria esse papel. 
Tais medidas reformistas, dentre outras coisas, buscam convencer professores a alterarem as suas práticas, incorporando novos saberes profissionais.

Em estudo realizado por Souza (2019), tem-se um inventário de artigos que versam sobre o ensino de matemática publicados na Revista de Educação. De outra parte, como o tema de estudo dessa autora atém-se, especificamente, à análise dos problemas aritméticos, seu texto não analisa os posicionamentos dos autores-professores dos artigos das revistas relativamente às propostas de Decroly. O presente texto tem esse objetivo, isto é, analisar os artigos considerando as reações e posicionamentos dos autores relativamente ao ensino globalizante e por centros de interesse da aritmética na escola primária. Ensino globalizante e centros de interesse para ensinar aritmética no curso primário?

$\mathrm{Na}$ atmosfera escolanovista das décadas que sucedem os anos 1920, como reagem os professores à vista de propostas globalizantes para o ensino da aritmética dos primeiros anos escolares? Ensino globalizante e centros de interesse para ensinar aritmética no curso primário?

\section{Ensino globalizante e centros de interesse para ensinar aritmética no curso primário?}

No inventário realizado por Souza (2019), é possível destacar dois textos onde estão presentes opiniões sobre o ensino globalizante e os centros de interesse para ensino da aritmética no curso primário.

QUADRO: ARTIGOS SELECIONADOS

\begin{tabular}{|l|l|l|}
\hline Título do artigo & Autor & Localização do artigo \\
\hline Sobre a Didática do cálculo & Renato Jardim & Revista Educação, 1934, v. VII, set., SP. \\
\hline O ensino da taboada no 2o. ano & $\begin{array}{l}\text { Luiz Gonzaga } \\
\text { Fleury }\end{array}$ & $\begin{array}{l}\text { Revista Educação, 1936, v. 13/14, n. 13/14, mar./ } \\
\text { jun., SP. Disponível em: https://repositorio.ufsc.br/ } \\
\text { xmlui/handle/123456789/128339. }\end{array}$ \\
\hline
\end{tabular}

FONTE: Elaborado pelo autor. 
O primeiro artigo a ser analisado é escrito pelo professor Renato Jardim (1867-1951). Sua carreira no magistério inclui a docência no Ginásio do Estado de Ribeirão Preto, terceira instituição pública de ensino secundário em São Paulo. Em 1917, torna-se diretor do estabelecimento. No ano de 1922, assume a direção da Escola Normal da Praça da República (CUNHA; SILVA, 2013). Pelos cargos que ocupa, por sua experiência profissional, Jardim revela-se como uma das vozes autorizadas a orientar professores e professorandos para o exercício do magistério primário.

No que toca às concepções de Renato Jardim sobre o escolanovismo, em análise de Cunha e Silva (2013) tem-se que:

Jardim adotava uma concepção bastante peculiar sobre a Escola Nova, defendendo que o núcleo da renovação educacional se encontrava não nas metas sociais almejadas, mas nos procedimentos pedagógicos criados e introduzidos nas escolas por diversos pensadores. Para ele, embora a nova pedagogia devesse responder às exigências determinadas pela sociedade moderna que emergia, a essência do escolanovismo residia nos métodos inovadores que visavam favorecer a plena realização das potencialidades dos educandos (p. 89).

De outra parte, estudos de Nery (2009) mostram que, por sua atuação, Renato Jardim não pode ser considerado como um "renovador": "foi mais um 'moderado', no sentido em que defendia melhorias no ensino, mas via com cautela o emprego de algumas ideias importadas" (p. 95).

$\mathrm{O}$ artigo de Renato Jardim a ser analisado, relativamente à matemática do ensino primário, parece corroborar com esse perfil traçado por historiadores da educação. "Sobre a Didática do cálculo" é texto que mostra a seus leitores como esse experiente professor entende o ensino globalizante, mostrando suas ressalvas quanto à aritmética a estar sujeita a essa metodologia e a dos centros de interesse. O texto refere-se, na verdade, à transcrição de palestra de Jardim em evento do dia 17 de abril de 1934, para professoras do ensino primário.

Evocando a sua própria trajetória como aluno, Jardim trata dos ensinos de matemática. Logo, destaca: "Passei pelo meu curso de matemática, e dele saí, tão só com estes dois magros proveitos: a convicção da minha inferioridade intelectual e... a ojeriza à matemática" (JARDIM, 1934, p. 6). Na avaliação desse seu próprio processo, mais adiante o autor pondera: 
O primeiro dano que do 'matemático' advém ao ensino é que ele, ignorando o espírito da criança, pensa que as generalidades em que se apoia e com que se satisfaz o seu, recebe-las-á também a mente infantil. Daí, os inidôneos processos didático que de século em século vêm torturando o pobre aluno (JARDIM, 1934, p. 9, aspas e itálico do autor).

Esta é uma consideração que parece comum às autoridades do ensino, ou àqueles professores que, de algum modo, veiculam novas propostas, ao tratarem dos ensinos das diferentes matérias e, em particular, da matemática: a crítica aos tempos de pedagogia tradicional. O novo, o ideário escolanovista, destaca o aluno, a necessidade de o professor considerar "o espírito da criança" para os ensinos. As críticas dirigem-se à pedagogia tradicional, considerada como prática pedagógica que trata os conteúdos por si mesmos, desconsiderando o aluno.

Contrapondo-se à velha escola, Jardim evoca os novos tempos, tempos da Escola Nova, da escola ativa, onde estão presentes novas práticas dos professores, guiadas pelo ensino globalizante, pelos centros de interesse, pelo método de projetos etc.:

Acho-me, por honrosa e grata mercê, em uma assembleia de exímias e devotadas professoras, para as quais a "escola ativa" é uma realidade, pelas quais, direi melhor, é a "escola ativa", entre nós, uma realidade. No regime desse tipo de escola, o cálculo sobre números e quantidades, a avaliação de áreas e quejandos assuntos da nobre disciplina matemática, exercitam-se, não já por antiquados processos, a que caiba a habitual crítica, justa, à qual também eu, vítima deles, trago, o direito, o meu pequeno contingente, mas exercitam-se, sim, tais atividades, globalizadamente com os demais objetos do programa escolar, nos "jogos", nos "centros de interesse", na execução de "projetos", regime esse em que a atividade espontânea do aprendiz supre, e elimina, o arbitrário dogmatismo da velha didática (JARDIM, 1934, p. 12, itálico e aspas do autor).

Desse modo, Renato Jardim manifesta que, em teoria, parece, tudo vai bem com a escola ativa. Mas como será a prática efetiva das propostas em ação? Apesar da dúvida inicial, relativa ao "como fazer", Jardim pondera: "Não ignoro que as coisas da aritmética se aprendem através de atividades do pequeno escolar quando submetido ao 'método de projetos' ou quando entretido no desdobramento de um 'centro de interesses"”. Há, assim, pos- 
sibilidades de ensino e aprendizagem da aritmética pela atividade do aluno. E os centros de interesses são uma das possibilidades de ensino da moderna pedagogia da escola ativa.

A dúvida de Renato Jardim, no entanto, não se manifesta na possibilidade que a escola ativa tem de ensinar a aritmética. A dúvida do autor refere-se ao confronto da aritmética ensinada pela atividade do aluno versus aquela oficialmente posta num programa de ensino. Diz Jardim:

\begin{abstract}
Mas, se estão acertados os métodos da escola ativa, neles a 'globalização' é, contudo, lícito inquirir-se: 'Os conhecimentos matemáticos, da aritmética, digamos, obtidos, como por acidente, através do desenvolvimento de um ou mais 'centros de interesse', em dado período escolar, são suficientes? Satisfazem por si sós?' - 'Esses conhecimentos, empiricamente colhidos, resultantes da atividade e experiência da criança, como convêm que sejam, deverão ser deixados tal como os colheu a mente do educando? - 'Convém a intervenção de um trabalho especial, destinado a completá-los, a consolidá-los, a enfeixá-los em um sistema? ... 'E circunstância especial - se apenas nos achamos, como de outro modo não poderia deixar de ser, em fase de transição, em fase de passagem da 'escola clássica' para a 'escola nova', vigente ainda o 'programa por matérias', como praticar o ensino globalizado e ao mesmo tempo não desatender ao programa prescrito?' (JARDIM, 1934, p. 12, itálico e aspas do autor).
\end{abstract}

Para essa dúvida - programas de ensino versus escola ativa -, Jardim manifesta não ter resposta pronta, encerrando a sua palestra. Assim, revela-se, em específico, o caráter de moderado de Jardim, mencionado anteriormente. Sim aos novos métodos; não a seu uso irrestrito face aos programas de ensino e conteúdos que deverão ser ensinados.

O segundo artigo tem autoria de Luiz Gonzaga Fleury, goiano, descendente de família influente na política de seu estado. Fleury também se liga à geração de professores de destaque vindos da Escola Normal paulista. Em 1910, com 19 anos, obtém diploma de "professor normalista" pela Escola Normal Secundária da Praça da República, em São Paulo. Fleury revela-se intelectual de destaque em seu tempo, pois dedica-se posteriormente à sua formação docente a estudos de filosofia, psicologia, lógica, economia, política, sociologia, direito, entre outras áreas (GOULART, 2015). 
A inserção de Fleury no magistério paulista, a partir de 1910, ocorreu em um período marcado pelo processo de construção de grupos escolares como uma nova forma de organização administrativa e pedagógica do ensino público primário, visando não apenas à implantação de escolas modernas, de 'boa' qualidade, atendendo às exigências da urbanização, como também à implantação de um plano do Governo para reorganizar o ensino popular (GOULART, 2015, p. 139).

Dentre os inúmeros postos assumidos por Fleury no ensino paulista, destaque-se as funções de diretor escolar e inspetor do ensino. Fora do ensino, propriamente, mas ainda dentro do campo da educação, foi escritor e tradutor de textos de autores estrangeiros para a Revista Educação, de São Paulo, durante 11 anos:

A Revista Educação se mostrou um periódico de intenso investimento da produção intelectual do Prof. Fleury, sendo possível encontrar o maior número de publicações de seus artigos. Seu destaque nesse periódico não se restringiu apenas aos textos traduzidos de autores franceses, mas conquistou reconhecimento pela publicação de diversos textos de caráter científico, versando sobre diferentes temáticas. Era uma publicação composta por vinte e um artigos e dois textos de traduções, distribuídos numa periodicidade de onze anos, entre 1928 e 1939 (GOULART, 2015, p. 142).

Para os objetivos deste texto, interessa-nos analisar o artigo escrito por Fleury, intitulado "O ensino da taboada no 2o. ano", que é publicado em 1936. Escrito em quatro páginas - diferentemente do texto de Jardim, na transcrição de sua palestra, que ganhou 13 páginas -, tem por objetivo divulgar orientações de práticas pedagógicas aos professores para o ensino da tabuada de multiplicação. Desde a primeira frase do texto, o autor pontua a natureza da sua escrita como sendo algo prático para orientar professores sobre o "como fazer", atendendo às expectativas de seu público leitor: "Queixam-se professores de que a Revista Educação tem aspecto quase exclusivamente teórico e opinam que deveria, pelo contrário, tê-lo quase exclusivamente prático" (FLEURY, 1936, p. 38). O autor mostra-se em acordo com essas críticas e destaca que "um dos preceitos didáticos mais legítimos é o que diz - 'teoria pouca, exercícios muitos”' (1936, p. 38).

A proposta prática para ensino da tabuada de multiplicação preconizada por Fleury refere-se a artifícios a serem utilizados pelos professores de modo a que os alunos memorizem a tabuada. Antes, porém, de apresentar como levar os 
alunos a memorizarem a tabuada, Fleury defende-se previamente das possíveis críticas que poderá receber ao propor processos de memorização em meio à vaga modernizadora do ensino:

Já estamos a ver o arrepio de horror pedagógico de não poucos professores, mais ou menos intransigentes em questões didáticas, que exclamarão: Pois ainda se vem falar de ensino e memorização de tabuada, numa época em que se preconizam os métodos globais, a aprendizagem motivada, espontânea e ativa? (FLEURY, 1936, p. 38).

Por que, então, ensinar a memorizar a tabuada? Fleury responde à questão de modo enfático:

Em aritmética, pelo menos, os métodos globais não oferecem oportunidades suficientes para exercícios reiterados, para a aquisição de técnicas que convêm serem dominadas desde logo e perfeitamente. (...) E já não são poucos os modernos didatas que o reconhecem expressamente e que recomendam o emprego de exercícios formais na escola (e não apenas em aritmética) para suprir as deficiências inerentes à globalização (FLEURY, 1936, p. 39).

De maneira a reforçar a sua posição, Fleury apropria-se de trechos escritos por Miguel Aguayo, reconhecido autor de obras didático-pedagógicas: "Não devem ser descuidados e menos ainda suprimidos os trabalhos e exercícios que, faltos embora de interesse, são indispensáveis para adquirir facilidade e práticas ou formar certos hábitos e atitudes mentais exigidos por todo trabalho de boa qualidade" (AGUAYO apud FLEURY, 1936, p. 39).

A partir dessa introdução desse seu artigo, Fleury passa a descrever como levar os alunos a memorizarem a tabuada de multiplicação no segundo ano primário. Indica a associação da multiplicação com adições sucessivas, articulando o ensino com historinhas e desafios para os alunos.

Como Jardim, Fleury mostra que suas posições didático-pedagógicas não seguem uma linha orientada pela lógica das teorias. Sua inserção nas práticas pedagógicas, sua experiência como professor, diretor, professor obrigam-no a considerar os problemas das práticas para além de uma doutrina única, de uma filiação sem questionamentos ao escolanovismo. Nesse caso, também poderia ser considerado um "moderado", não um pleno "reformador". 


\section{Considerações finais}

É pouco provável que um professor que ensina matemática hoje não tenha passado por experiências de globalização. Guardado o distanciamento histórico, o termo poderá ser entendido na atualidade como interdisciplinaridade. Assim, a partir de uma temática presente na realidade social e do aluno, as tradicionais matérias ou disciplinas escolares, de modo integrado, devem ser mobilizadas para fornecerem subsídios para o melhor entendimento dessa temática pelo aluno. Os conteúdos não mais representam um fim em si mesmos. São ferramentas para compreensão de uma situação real considerada importante. Assim, possivelmente seja muito familiar aos professores hoje a interrogação de Renato Jardim: como cumprir os programas atrelando a matemática num projeto interdisciplinar, num projeto de ensino globalizado, tendo em vista os centros de interesse? A matéria a ser cumprida no ensino caberá no projeto globalizante?

Diferentemente de Jardim, Fleury advoga, mais incisivamente, um recuo à tradição para o ensino de matemática (aritmética) nos primeiros anos escolares, tendo em conta a prática do exercício, dos numerosos exercícios de fixação. Tal prática pedagógica possivelmente também está presente no senso comum pedagógico dos ensinos de matemática hoje. Sem praticar, sem resolver exercícios de matemática (aritmética), os alunos não aprendem. E o ensino globalizante, por centros de interesse, é considerado pouco afeito a reiterações, a treinamentos e exercícios etc.

Em síntese, as observações e dúvidas dos professores Jardim e Fleury revelam permanências, hoje, de elementos do que poderíamos chamar de uma "cultura escolar do ensino de matemática nos primeiros anos escolares": o cumprimento das lições que deverão ser dadas (os conteúdos do programa de ensino) e a prática de numerosos exercícios que atestem o domínio aritmético pelo aluno. No primeiro caso, ao que tudo indica, pouco importa a concepção pedagógica que se está adotando. O rol dos conteúdos de ensino tem prioridade. No segundo caso, o treino e memorização são elementos que vêm de longa data no ensino, principalmente no ensino de matemática. São ecos da história da educação matemática ouvidos e pronunciados por professores da atualidade.

São letra morta as propostas pedagógicas inovadoras de Decroly que aportam no Brasil em termos da aritmética para o ensino primário? A ruptura com as disciplinas enfeixadas em si mesmas, em prol de um ensino de conjunto, global, terá sido apenas um ideário pedagógico? Em caso negativo, que elementos decrolianos são apropriados no ensino primário brasileiro de modo 
a integrar a matemática numa proposta globalizante? Ou, ainda: como as propostas de ensino globalizante modificam a matemática a ser ensinada no curso primário? E, também: como tais propostas alteram os saberes de formação dos professores que irão ensinar matemática? Tais questões somente poderão ter resposta a partir de estudos mais aprofundados sobre o tema, como os que vêm sendo desenvolvidos e são citados ao início deste texto.

\section{REFERÊNCIAS}

CARVALHO, L. M.; CORDEIRO, J. Brasil-Portugal nos circuitos do discurso pedagógico especializado (1920-1935): um estudo histórico-comparativo de publicações de Educação. Lisboa: EDUCA, 2002. Cadernos Prestige 9.

CATANI, D. B. A imprensa periódica educacional: as revistas de ensino e o estudo do campo educacional. Educação e Filosofia, v. 10, n. 20, p. 115-130, jul./dez. 1996. Disponível em: http://www.seer.ufu.br/index.php/EducacaoFilosofia/article/view/928/842. Acesso em: 06 mai.2019.

CUNHA, M. V.; SILVA, T. Concepções políticas e educacionais de Renato Jardim na década de 1930. Revista HISTEDBR On-line, v. 13, n. 53, p. 78-91, 2013. Disponível em: https://repositorio.unesp.br/bitstream/handle/11449/125173/ISSN1676-2578-201313-53-78-91.pdf?sequence=1\&isAllowed=y. Acesso em: 06 mai. 2019.

DECROLY, O. La fonction de globalisation et l'enseignement. M. Lamertin, Bruxelles, 1929, 59p. In: DECROLY, O. Le programme d'une école dans la vie. Collection Pédagogues du Monde Entier. Paris: Éditions Fabert, 2009.

FERNANDES, J. C. B. Centros de Interesse no ensino primário: há saberes aritméticos? Anais do XVII Seminário Temático: Materiais Didáticos e História da Educação Matemática. Aracaju, Sergipe, 29 de abril a 1o de maio de 2019. Disponível em: https:// drive.google.com/file/d/0B6QMqAPY7A8uVFZkMINtbU1mVkhfZ1ljcXlvNkNjRFI 2OXhN/view. Acesso em: 10 mai. 2019.

FLEURY, L. G. O ensino da taboada no $2^{\circ}$ anno. Revista Educação, 1936, v. 13/14, n. 13/14, mar./jun., SP. Disponível em: https://repositorio.ufsc.br/xmlui/handle/123456789/128339. Acesso em: 02 mai. 2019.

GOULART, I. C. V. O ensino da leitura na produção escrita de Luiz Gonzaga Fleury, entre 1922 a 1936. Revista Brasileira de História da Educação. Maringá, PR, v. 15, n. 2 (38), p. 133-158, mai/ago. 2015.

JARDIM, R. Sobre a Didática do calculo. Revista Educação, 1934, v. VII, set., SP. Disponível em: http://repositorio.ufsc.br/xmlui/handle/123456789/99962. Acesso em: 02 mai. 2019. 
NERY, A. C. B. A Sociedade de Educação de São Paulo-embates no campo educacional (1922-1931). São Paulo: Editora da UNESP, 2009.

REZENDE, A. M. S. Maria Montessori e os materiais para o ensino: a materialização de saberes. Anais do XVII Seminário Temático: Materiais Didáticos e História da Educação Matemática. Aracaju, Sergipe, 29 de abril a 1 o de maio de 2019. Disponível em: https:/drive.google.com/file/d/0B6QMqAPY7A8ucjhERnRsT1lHbGx4azdhVHV 1WkxZLWFwWHIR/view. Acesso em: 10 mai. 2019.

SOUZA, A. F. Saberes para ensinar problemas: uma análise dos artigos da Revista Educação (São Paulo, 1933-1943). Anais do XVII Seminário Temático: Materiais Didáticos e História da Educação Matemática. Aracaju, Sergipe, 29 de abril a 1o de maio de 2019. Disponível em: https://drive.google.com/file/d/13pv0KqB0uKHT4A_ZwucVHAjxEUs_yBHG/view. Acesso em: 09 mai. 2019.

WAGNON, S. Introduction et présentation des textes. In: DECROLY, O. Le programme d'une école dans la vie. Collection Pédagogues du Monde Entier. Paris: Éditions Fabert, 2009.

Texto recebido em 12 de maio de 2019.

Texto aprovado em 22 de maio de 2019. 